\title{
Keratosis follicularis spinulosa decalvans: confirmation of linkage to Xp22.13-p22.2
}

Mary E M Porteous, Lisa Strain, Lindsay J Logie, Robert M Herd, E Claire Benton

\section{Abstract}

Keratosis follicularis spinulosa decalvans (KFSD) is a rare, $X$ linked disorder with skin and eye involvement (MIM 308800). We have studied a large British family with KFSD using polymorphic markers from Xp21-p23 and obtained a lod score of 2.056 at $\theta=0$ with markers proximal and distal to the KFSD candidate region
Xp22.13-p22.2 identified by Oosterwijk et al. Our data confirm the linkage to Xp22.13-p22.2 observed in the previously reported Dutch family, but fail to narrow the candidate interval for the KFSD locus. (F Med Genet 1998;35:336-337)

Keywords: KFSD; X linked; Xp22.13-p22.2
II

III

Human Genetics Unit, Western General Hospital, Crewe Road, Edinburgh EH4 2XU, UK

M E M Porteous

L Strain

L J Logie

University

Department of

Dermatology, Royal

Infirmary of

Edinburgh, Edinburgh

EH3 9YW, UK

R M Herd

E C Benton

\section{Correspondence to:} Dr Porteous.

Received 14 February 1997 Revised version accepted for publication 25 September 1997

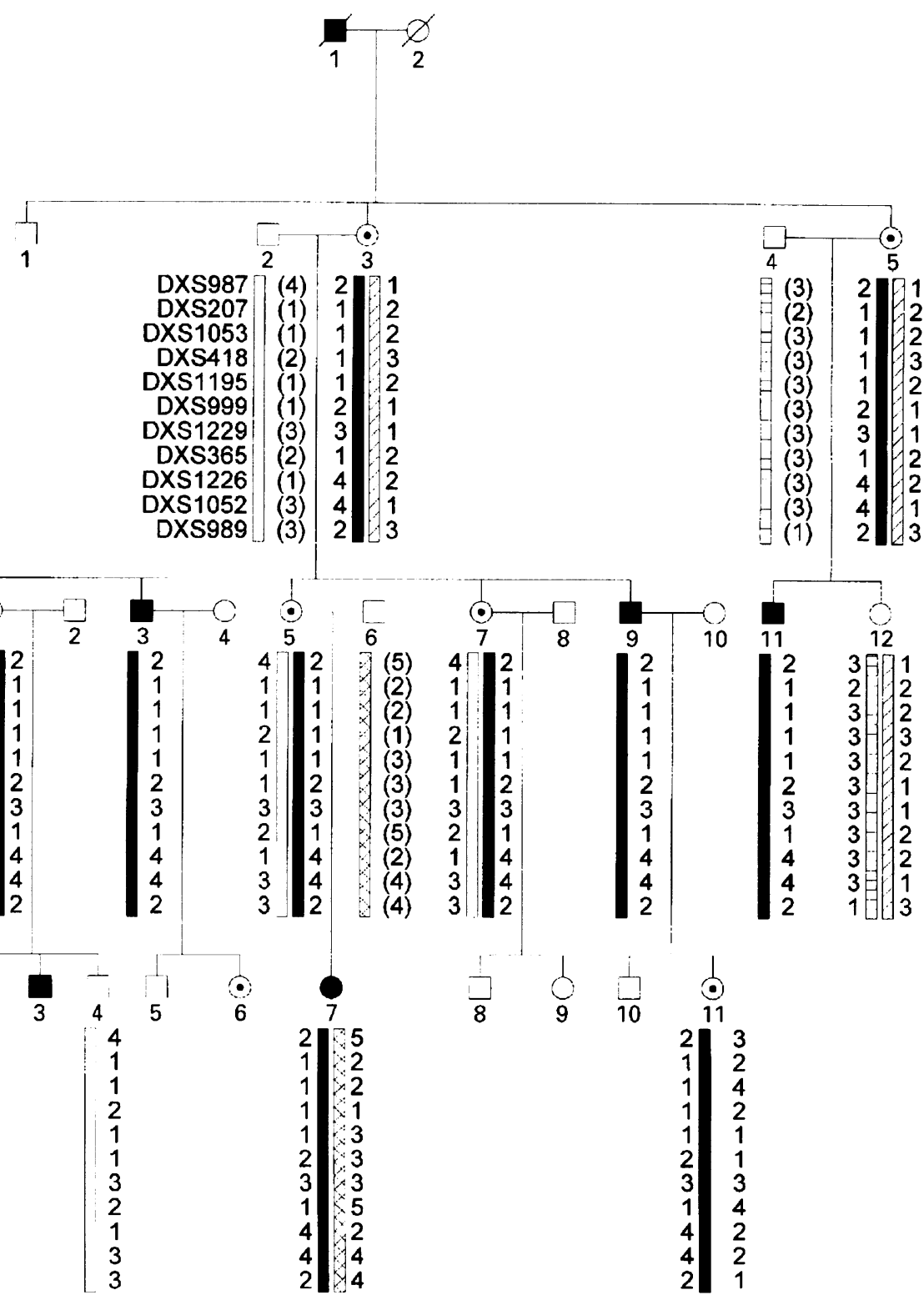

Figure 1 Pedigree of KFSD family. III.3: follicular hyperkeratosis, photophobia, III. 9: follicular hyperkeratosis, photophobia, III. 11: follicular hyperkeratosis, photophobia, entropion, recurrent blepharitis, IV.2: keratosis pilaris, IV.3. keratosis pilaris, IV.7: keratosis pilaris, calcaneal hyperkeratosis, photophobia, IV.11: follicular hyperkeratosis, photophobia. Haplotypes are shown for (telomere to centromere) DXS987, DXS207, DXS1053, DXS418, DXS1195, DXS999, DXS1229, DXS365, DXS1226, DXS1052, and DXS989, a distance of $16.2 \mathrm{cM}$. 
Table 1 Results of two point linkage analysis

\begin{tabular}{llllllll}
\hline \multicolumn{7}{l}{ Locus } & \multicolumn{7}{l}{ Recombination fraction $(\theta)$} \\
\cline { 2 - 8 } & 0 & 0.01 & 0.05 & 0.1 & 0.2 & 0.3 & 0.4 \\
\hline DXS987 & 2.056 & 2.023 & 1.888 & 1.709 & 1.315 & 0.866 & 0.384 \\
DXS207 & 1.153 & 1.333 & 1.052 & 0.943 & 0.702 & 0.428 & 0.147 \\
DXS1053 & 1.153 & 1.333 & 1.052 & 0.943 & 0.702 & 0.428 & 0.147 \\
DXS418 & 1.153 & 1.333 & 1.052 & 0.943 & 0.702 & 0.428 & 0.147 \\
DXS1195 & 1.153 & 1.333 & 1.052 & 0.943 & 0.702 & 0.428 & 0.147 \\
DXS999 & 1.755 & 1.722 & 1.587 & 1.408 & 1.014 & 0.575 & 0.163 \\
DXS1229 & 1.028 & 1.011 & 0.938 & 0.841 & 0.623 & 0.376 & 0.126 \\
DXS365 & 1.755 & 1.722 & 1.587 & 1.408 & 1.014 & 0.575 & 0.163 \\
DXS1226 & 2.056 & 2.023 & 1.888 & 1.709 & 1.315 & 0.866 & 0.384 \\
DXS1052 & 2.056 & 2.023 & 1.888 & 1.709 & 1.315 & 0.866 & 0.384 \\
DXS989 & 1.755 & 1.722 & 1.587 & 1.408 & 1.014 & 0.575 & 0.163 \\
\hline
\end{tabular}

Keratosis follicularis spinulosa decalvans (KFSD) is a rare, $\mathrm{X}$ linked genodermatosis characterised by generalised follicular hyperkeratosis, scarring alopecia involving the scalp, eyebrows, and eyelashes, and corneal dystrophy. Symptoms develop in early childhood with photophobia and keratosis pilaris followed by progressive scarring alopecia. The symptoms diminish with age and the long term prognosis for vision is good. Female carriers show a milder version of the phenotype in about $50 \%$ of cases. ${ }^{1}$ KFSD was first described by Lameris in $1905^{2}$ with a more detailed phenotype in the same large Dutch family being defined by Siemens in $1926 .^{3}$ In 1992 this family was reassessed clinically ${ }^{4}$ and in 1995 the KFSD locus was mapped to Xp22.13-p22.2 with a maximum lod score of 12.07 for DXS365 at $\theta=0 .{ }^{5}$ Further refinement of the candidate interval placed the KFSD locus between DXS7161 and DXS1226, a map distance of 1-2 Mb. ${ }^{6}$

Materials, methods, and results

DNA was collected from members of a large British family (fig 1) with characteristic clinical features of KFSD. The family had been previously reported as part of a clinical study. ${ }^{8}$ Genomic DNA was extracted from EDTA blood samples by protease $K$ treatment followed by salt extraction.

Eleven microsatellite markers covering a region $5.1 \mathrm{Mb}$ telomeric to and $1.7 \mathrm{Mb}$ centromeric to the candidate interval defined in the Dutch KFSD family were chosen. Primer sequences and cycling conditions for the markers were obtained from the Genome database (GDB) and one primer of each pair was fluorescein labelled at the $5^{\prime}$ end during synthesis. PCR reactions were carried out in 50 $\mu \mathrm{l}$ volumes and contained $10 \mathrm{mmol} / \mathrm{l}$ Tris- $\mathrm{HCl}$ (pH 8.3), $50 \mathrm{mmol} / 1 \mathrm{KCl}, 1.5 \mathrm{mmol} / 1 \mathrm{MgCl}_{2}$, $200 \mu \mathrm{mol} / 1 \mathrm{dNTPs}, 0.1 \mu \mathrm{mol} / 1$ each primer, $250 \mathrm{ng}$ genomic DNA, and $5 \mathrm{U} T a q$ polymerase. PCR products were analysed on an automated laser fluorescent sequencer (ALF, Pharmacia).

Two point linkage analysis was performed using the MLINK program version $5.2^{\circ}$ assuming a gene frequency of $0.00001, \mathrm{X}$ linkage, and a penetrance of 0.5 in female gene carriers. Penetrance in males was assumed to be complete. Allele frequencies were assumed to be equal.

No recombination between the KFSD locus and the marker set was observed. The haplotypes obtained are shown in fig 1. Markers DXS987, DXS418, and DXS989 were all fully informative and showed tight linkage to the KFSD locus with a maximum lod score in each case of 2.056 at $\theta=0$ (table 1 ).

\section{Discussion}

To our knowledge, this family in which KFSD is segregating is only the second of appropriate size and structure for linkage analysis. Our linkage data confirm the previous finding of a locus for KFSD in the region of Xp22.13p22.2 bounded by DXS7161 and DXS1226. The marker DXS989 is centromeric to DXS274 while DXS987 is telomeric to DXS418. The lack of recombination observed in our family with these markers prevents any further narrowing of the candidate interval for the KFSD locus.

Because of the variability of the clinical phenotype in carrier females, some authors have suggested that KFSD is a sex limited, autosomal dominant disease. ${ }^{10}{ }^{11}$ Our family has a severely affected female member (IV.7), but linkage analysis is strongly suggestive of a KFSD locus in the same region of the $\mathrm{X}$ chromosome as that found in the large Dutch family. KFSD has features in common with both ulerythema ophryogenes (UO) and ichthyosis follicularis (IF), but neither disorder has photophobia as a significant feature. However, in small families with skin manifestations resembling KFSD, diagnostic dificulties can occur. To our knowledge, male to male transmission has not been documented in a proven case of KFSD, and we conclude that evidence to date is consistent with one $\mathrm{X}$ linked locus in this disorder.

1 Oosterwijk JC, Nelen M, van Zandvoort PM, et al. Linkage analysis of keratosis follicularis spinulosa decalvans and regional assignment to human chromosome Xp21.2-p22.2. Am $\mathcal{F}$ Hum Genet 1992;50:801-7.

2 Lameris HJ. Ichthyosis follicularis. Ned Tijdschr Geneeskd 1905;41:1524.

3 Siemens HW. Keratosis follicularis spinulosa decalvans. Arch Dermatol Syphilol 1926;151:384-7.

4 van Osch LDM, Oranje AP, Keukens FM, van Voorst Vader PC, Veldman E. Keratosis follicularis spinulosa decalvans: a family study of seven male cases and six female carriers. $\mathcal{F}$ Med Genet 1992;29:36-40.

5 Oosterwijk JC, van der Wielen MJR, van de Vosse E Voorhoeve E. Refinement of the localisation of the X linked keratosis follicularis spinulosa decalvans (KFSD) gene in Xp22.13-p22.2. F Med Genet 1995;32:736-9.

6 Van de Vosse E, Bergen AAB, Meershoek EJ, et al. An $\mathrm{Xp22.1-p22.2} \mathrm{YAC} \mathrm{contig} \mathrm{encompassing} \mathrm{the} \mathrm{disease} \mathrm{loci}$ for RS, KFSD, CLS, HYP and RP15: refined localisation of RS. Eur $\mathcal{F}$ Hum Genet 1996;4:101-4.

7 map.html@cedar.genetics.soton.ac.uk

8 Herd RM, Benton EC. Keratosis follicularis spinulosa decalvans: report of a new pedigree. $B r f$ Dermatol 1996;134:138-42.

9 Lathrop GM, Lalouel JM. Easy calculations of lod scores and genetic risk on small computers. Am $\mathcal{F}$ Hum Genet 1984;36:460-5.

10 Kuokkannen K. Keratosis follicularis spinulosa decalvans in a family from northern Finland. Acta Dermatol Venereo 971;51:146-50.

11 Rand R, Baden HP. Keratosis follicularis spinulosa decalvans. Report of two cases and literature review. Arch Dermatol 1983;119:22-6. 